\title{
Phytobioactive compound-based nanodelivery systems for the treatment of type 2 diabetes mellitus - current status
}

\author{
Palanivel Ganesan ${ }^{1,2}$ \\ Palanisamy Arulselvan ${ }^{3}$ \\ Dong-Kug Choi ${ }^{1,2}$ \\ 'Nanotechnology Research Center \\ and Department of Applied \\ Life Science, ${ }^{2}$ Department of \\ Biotechnology, College of Biomedical \\ and Health Science, Konkuk \\ University, Chungju, Republic of \\ Korea; ${ }^{3}$ Laboratory of Vaccines and \\ Immunotherapeutics, Institute of \\ Bioscience, Universiti Putra Malaysia, \\ Serdang, Malaysia
}

This article was published in the following Dove Press journal:

International Journal of Nanomedicine

9 February 2017

Number of times this article has been viewed

\begin{abstract}
Type 2 diabetes mellitus (T2DM) is a major chronic disease that is prevalent worldwide, and it is characterized by an increase in blood glucose, disturbances in the metabolism, and alteration in insulin secretion. Nowadays, food-based therapy has become an important treatment mode for type 2 diabetes, and phytobioactive compounds have gained an increasing amount of attention to this end because they have an effect on multiple biological functions, including the sustained secretion of insulin and regeneration of pancreatic islets cells. However, the poor solubility and lower permeability of these phyto products results in a loss of bioactivity during processing and oral delivery, leading to a significant reduction in the bioavailability of phytobioactive compounds to treat T2DM. Recently, nanotechnological systems have been developed for use as various types of carrier systems to improve the delivery of bioactive compounds and thus obtain a greater bioavailability. Furthermore, carrier systems in most nanodelivery systems are highly biocompatible, with nonimmunologic behavior, a high degree of biodegradability, and greater mucoadhesive strength. Therefore, this review focuses on the various types of nanodelivery systems that can be used for phytobioactive compounds in treating T2DM with greater antidiabetic effects. There is also additional focus on improving the effects of various phytobioactive compounds through nanotechnological delivery to ensure a highly efficient treatment of type 2 diabetes.
\end{abstract}

Keywords: type 2 diabetes, nanodelivery system, phytobioactive compounds, oral delivery

\section{Introduction}

Type 2 diabetes mellitus (T2DM) is a major chronic disease with an increasing prevalence worldwide, and it is a major burden in many developing and developed countries due to the numerous complications associated with the diseases. ${ }^{1,2}$ The disease associated with numerous factors, including genetics, age, lack of physical activity, food habits, high stress, inflammation, and obesity. Many factors related to this disease can be controlled through a change in lifestyle and activities. ${ }^{3,4}$ Inflammation for this disease, and the associated complications, can be effectively reduced by taking certain drugs, and recently, the consumption of phytobioactive compounds - such as polyphenols, flavanones, curcumin, terpenoids, and quercetin rich foods - has shown potential antidiabetic effects without any other complications. ${ }^{5,6}$ Many researchers have orally administered phytobioactive compounds to show its beneficial effect on T2DM and its complications. ${ }^{7-15}$ However, many food grade bioactive compounds taken through oral means undergo a substantial loss in bioactivity, and thereby, the antidiabetic activity of the phytobioactive compounds is diminished. 
Various nanodelivery systems have been developed to improve the oral bioavailability of phyto-based antidiabetic compounds and to ensure sustained antidiabetic activities. ${ }^{16}$ Baicalin successfully formulated nanostructured lipid carrier (NLC) delivery systems with particle sizes of $92 \mathrm{~nm}$, and these showed a higher antidiabetic activity with a sustained release of these compounds through oral delivery. ${ }^{17}$ Stevioside is another phyto compound that has shown improved antidiabetic activity via controlled release of the compounds through polyethylene glycol-polylactic acid nanoparticle delivery systems with a particle size of $150 \mathrm{~nm} .{ }^{18}$ In addition to the potential delivery of phytobioactive compounds for systematic circulation, many researchers are searching for effective delivery materials with highly nontoxic and nonmutagenic behavior as well as good water solubility. Although different nanodelivery systems plays a critical role in the delivery of active compounds to many diseases. ${ }^{19,20}$ Only a few novel nanodelivery systems, such as solid lipid nanoparticles, nano-phytosome, and nanoemulsion, have shown good efficacy in the delivery of phytobioactive compounds. Very recently controlled delivery of drugs was studied using nanowire systems, ${ }^{21-23}$ and their efficacy in delivery of drugs to the diabetic model is still limited. The current review presents the potential use of various nanoscale drug delivery systems for phyto-based bioactive compounds to treat $\mathrm{T} 2 \mathrm{DM}$ and its associated complications.

\section{The role of phytobioactive compounds in T2DM through oral delivery}

Traditional medicines have extensively used phytobioactive compounds to treat T2DM. ${ }^{24-31}$ These bioactive compounds, including but not limited to flavonoids, curcumin, polyphenol, and glucosides, have shown showed higher antidiabetic activity in various animal models. Due to the higher availability and multiple efficacies of these food-based medicines, they are currently in great demand in the market. The possible molecular mechanisms through which phyto compounds treat T2DM are shown in Figure 1. T2DM is associated with many complications, and few phytoactive compounds that are regularly consumed in food have shown multiple antidiabetic effects, thereby reducing drug loads during treatment. Curcumin from turmeric and bitter melon has shown multiple antidiabetic activities in various animal models. ${ }^{32-37}$ Although various food grade phytobioactive compounds are currently used in the treatment of T2DM, they lose efficacy during oral delivery, and therefore the development of novel delivery systems is crucial in improving their effects.

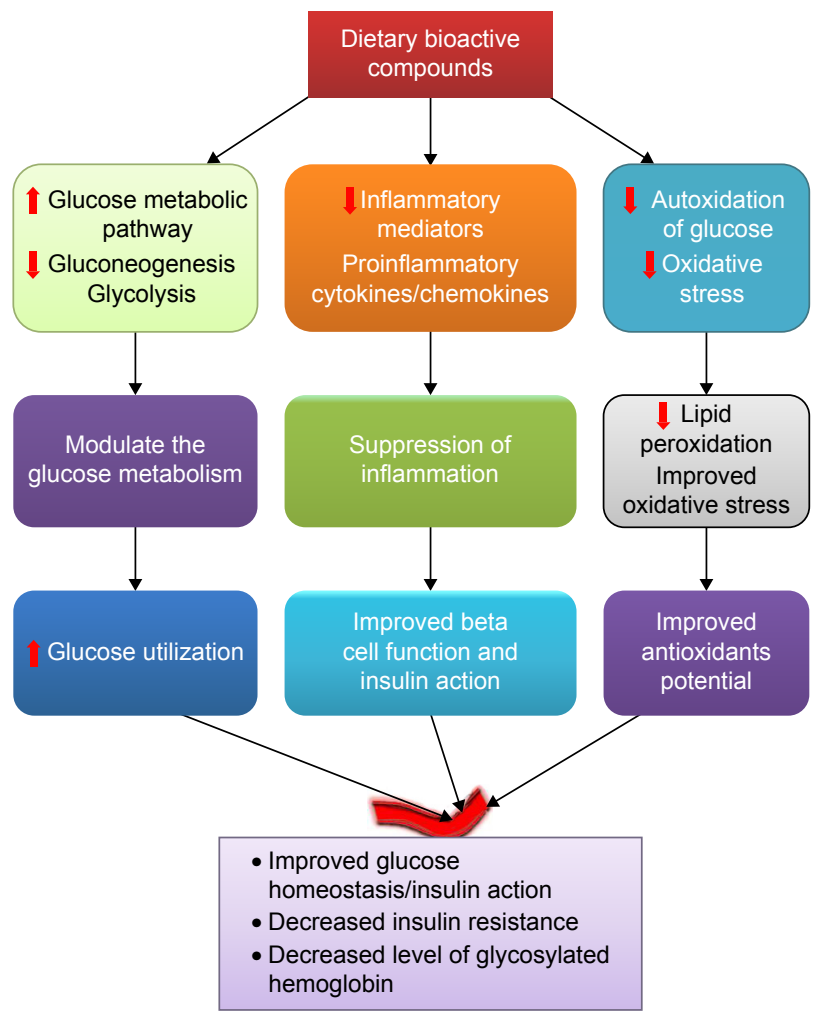

Figure I Possible molecular mechanism for phytobioactive compounds in treating type 2 diabetes.

Phytobioactive compounds are rich in antidiabetic foods or extracts, and their efficacy through oral delivery is relatively low due to the multiple challenges faced by the compounds, such as gastrointestinal fluid solubilization, cell uptake, and changes in the structure of the bioactive compounds. ${ }^{38-40}$ The bioavailability of antidiabetic phytobased bioactive compounds curcumin has been improved by coingesting them with certain lipids. ${ }^{41}$ In addition, curcumin delivery was greatly enhanced through the mixed lipid and protein-based digestible colloidal nanoparticles. ${ }^{40,42}$ Recently, alternative approaches have been proposed to improve the efficacy and sustained bioavailability through oral development of excipient foods rich in antidiabetic activities using various delivery technologies from macro to nanoscale, thereby limiting the digestion of these compounds through oral delivery. ${ }^{39,40,43-45}$

\section{Nanodelivery systems used to treat T2DM}

Currently, nanodelivery systems are an area of intense focus for the delivery of bioactive compounds through oral means to ensure effective treatment of various chronic diseases, including T2DM, hypertension, and cancer. Antidiabetic compounds, including curcumin and berberine, among other phyto compounds, have been effectively formulated 


\section{Functionalized nano- \\ compounds (oral delivery)}

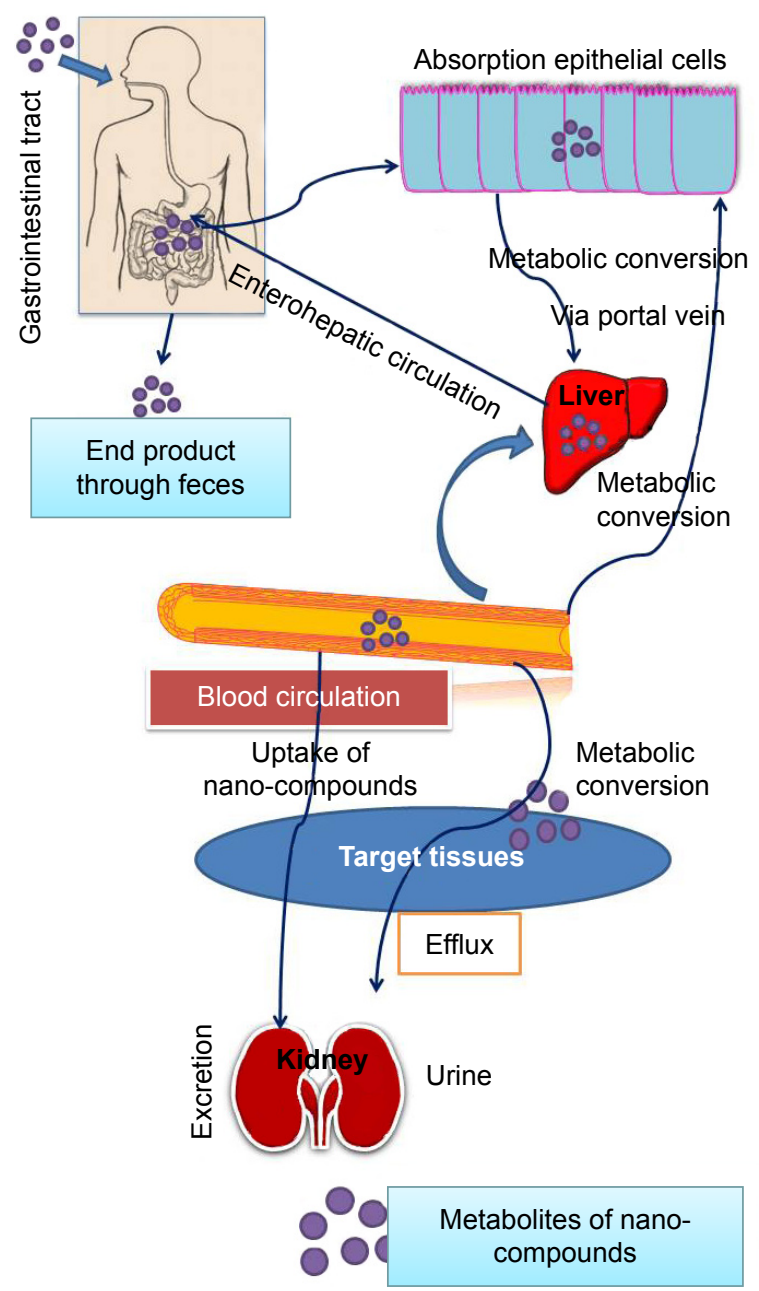

Figure 2 Possible nano phytobioactive compound bioavailability through oral delivery systems in humans.

using various nanodelivery technologies, resulting in higher antidiabetic potential in T2DM animal models. The effective oral delivery of nano phytobioactive compounds is shown in Figure 2. To ensure effective delivery of the bioactive compounds in the nanosystems, it is important to carefully design these delivery systems. Effective delivery and functional food development can be achieved through several approaches using nanoemulsions with improved delivery of lipid-soluble bioactive compounds. The delivery pathways for phytobioactive compound-based nanodelivery systems are shown in Figure 3. Several nanodelivery systems and their efficacy in treating T2DM are discussed further.

\section{Solid lipid nanoparticles}

Solid lipid nanoparticle delivery systems are used for the oral delivery of various antidiabetic compounds due to certain

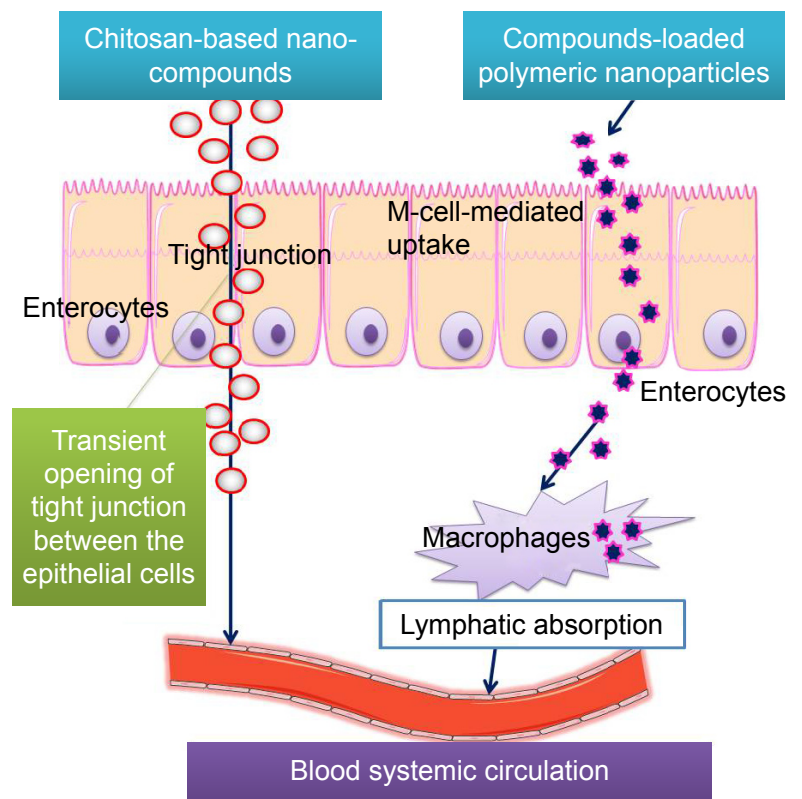

Figure 3 Possible delivery mechanism for phytobioactive compound-based nanodelivery systems.

advantages over conventional oral delivery systems, such as a higher bioavailability, lower toxicity, sustained delivery, higher cellular uptake, and macrophage distribution. ${ }^{46-50}$ Various animal models have shown a higher efficacy of these nanodelivery systems for oral delivery of various phyto-based bioactive compounds. Recently, berberine-loaded solid lipid nanoparticle delivery systems were developed with an average particle size of $\sim 76 \mathrm{~nm}$ and a uniform size, and treated rats showed a higher antidiabetic activity by suppressing gains in body weight, lowering fasting blood glucose levels, and promoting islet cell functions. The same research group also studied the effect of berberine-loaded solid lipid nanoparticles on the diabetic fatty liver and found that the drug's presence was $20 \times$ higher in the liver, thereby effectively preventing lipogenesis and enhancing lipolysis in the liver of diabetic mice models. ${ }^{51,52}$ In another study, berberine-loaded solid lipid nanoparticles were developed with a particle size of $\sim 154 \mathrm{~nm}$, showing an improved hypoglycemic effect in the C57BL/6 mice model of T2DM. ${ }^{53}$ Similarly, bioactive compounds from mistletoe have shown an enhanced antidiabetic effect in the T2DM animal model with a lowered hyperglycemic effect. ${ }^{46}$ However, other potentially active antidiabetic compounds, such as quercetin, curcumin, and catechin, have also been studied for formulation using solid lipid nanoparticles, but their potentiality in the diabetic animal model is still limited. Various studies have confirmed that solid lipid nanoparticles can be effectively used to deliver phyto-based bioactive compounds through oral administration in order to treat T2DM. 


\section{Nanostructured lipid carriers}

NLC are another type of lipid-based nanodelivery systems with certain advantages over solid lipid delivery systems, such as a lower particle size and improved loading capacity in order to obtain effective delivery of the phyto ingredients in the treatment of T2DM. ${ }^{54}$ Recently, baicallin was studied to develop NLC delivery systems, and the results indicated that a particle size of $\sim 92 \mathrm{~nm}$ showed an enhanced antidiabetic effect in the rat model with sustained release. ${ }^{17}$ As most antidiabetic phytobioactive compounds, such as quercetin, thymoquinone, and resveratrol, face significant challenges in delivery. NLC delivery systems enhanced those bioactive compounds delivery with sustained release. ${ }^{55-58}$ Baicalin-loaded NLC have shown a sustained release through oral delivery with a particle size of $\sim 244 \mathrm{~nm} .{ }^{59}$ A higher bioavailability with sustained release of quercetin was observed in quercetin-loaded NLC developed using a phase inversion method with a particle size of $\sim 32 \mathrm{~nm} .{ }^{60}$ In another study, quercetin-loaded NLC systems were developed with a particle size of $47 \mathrm{~nm}$, resulting in a higher bioaccessibility of $\sim 60 \%{ }^{61}$ Recently, cationic-modified NLC delivery systems were developed with quercetin with a particle size of $\sim 126 \mathrm{~nm}$, showing a higher bioavailability in lung, kidney, and liver tissues. ${ }^{62}$ Although various phyto-derived antidiabetic compounds have shown a sustained release in oral studies, their bioavailability in the diabetic animal model is still limited. Thus, NLC systems can be considered as novel oral delivery systems with sustained release of the antidiabetic phyto compounds.

\section{Nanoemulsions}

Nanoemulsions greatly improve the delivery of various lipophilic bioactive compounds with high antidiabetic properties by providing a high stability of the compounds along with an increased bioavailability ${ }^{63-66}$ Recently, bitter gourd seed oil nanoemulsions containing $50 \% \alpha$-eleostearic acid were studied in the diabetic rat model. The results indicated that bitter gourd seed oil nanoemulsions with a particle size of $<100 \mathrm{~nm}$ were highly stable and could deliver enhanced antidiabetic properties through oral administration. ${ }^{67}$ The same research group also studied the effect of gourd seed oil nanoemulsion with a higher cellular uptake and prolonged antioxidant activities. ${ }^{68}$ In another study, alpha-tocopherol-loaded nanoemulsions with various particle sizes showed improved protective behavior in various organs, especially in streptozotocin-induced diabetic rat model. ${ }^{16}$ Similarly, many other phyto-derived bioactive compounds, including curcumin or quercetin, have shown an enhanced bioavailability through nanoemulsion delivery systems. A curcumin-encapsulated nanoemulsion was prepared with a particle size of $\sim 130 \mathrm{~nm}$, and it showed improved oral bioavailability in addition to liver protection. ${ }^{69}$ The quercetin-loaded nanoemulsion was also studied to provide efficient oral delivery of these compounds, quercetin was found to be highly protected through these delivery systems, with improved antioxidant activity along with no toxicity of the carrier system..$^{70,71}$ Many recent studies have confirmed that naturally derived bioactive compounds can be efficiently delivered through oral means using nanoemulsion. However, many studies are still needed, in particular to determine the role of the individual compounds in the diabetic model when this delivery system is used.

\section{Nanoliposomes}

Nanoliposomes are effective in delivering bioactive compounds that are both hydrophilic and hydrophobic with enhanced stability, efficacy, and bioavailability along with a lower particle size. ${ }^{72-76}$ The delivery of phytobioactive compounds with antidiabetic properties was greatly enhanced through the nanoliposome systems ${ }^{72,75-77}$ Recently, Orthosiphon stamineus, an antidiabetic medicinal herbal extract, was studied with a nanoliposome system in terms of its efficacy. The study showed that this extract can be effectively loaded into nanoliposome systems with a particle size of $152 \mathrm{~nm}$ to improve the antioxidant properties. ${ }^{78}$ Similarly, resveratrol, another antidiabetic compound, was studied for its oral bioavailability in an animal model when administered using nanoliposome systems. The results indicated that the animal group treated with resveratrol-loaded nanoliposome showed a 2 times increase in the bioavailability of resveratrol than the control group. ${ }^{79}$ Recently, catechin was successfully encapsulated using a nanoliposome system and was studied to develop functional food. Researchers found that catechin-loaded nanoliposomes can efficiently protect catechins from various factors, and these could be used as a possible functional food to deliver catechins. ${ }^{80}$ Folic acid-functionalized insulin-loaded liposomes were studied, and these showed enhanced bioavailability of insulin in the animal model through oral administration. ${ }^{81}$ Although many antidiabetic phytobioactive compounds have been successfully studied for their oral bioavailability and their efficacy in reaching circulation systems, nanoliposomes loaded with phytobioactive compounds in antidiabetic animal models still have limited use. 


\section{Nanosuspensions}

Nanosuspensions are delivery techniques for oral administration of active ingredients in the liquid phase with a particle size of $<1 \mu \mathrm{m}$, and these are prepared using various techniques, including wet or dry milling. ${ }^{82-85}$ Many phyto ingredients have been effectively prepared using nanosuspension techniques and have shown more effective antidiabetic effects than regular systems. ${ }^{86,87}$ Recently antidiabetic compounds, namely gymnemic acids, were prepared using a nanosuspension method with enhanced bioavailability. ${ }^{86}$ The same research group also studied the effect of those gymnemic acid nanosuspensions in humans and found that an enhanced antidiabetic effect with a greater glucose-lowering effect in humans ${ }^{88}$ Similarly, berberine nanosuspensions, another antidiabetic compound, showed an improved antidiabetic effect in T2DM animal models at a low dosage level. Similarly, other active phyto compounds, such as quercetin, have shown antidiabetic effects, and were studied in terms of their efficacy in oral delivery through nanosuspensions in order to prevent their loss of bioactivity. Quercetin nanosuspension with a uniform size have shown a higher bioavailability through oral delivery, with a $70 \times$ increase relative to control quercetin. ${ }^{89}$ In another study, curcumin-loaded nanosuspensions were prepared with a particle size of $210 \mathrm{~nm}$, and these showed an enhanced absorption of curcumin through various digestive system parts with a higher change in confirmation and a fluidity change of the intestinal mucosal membrane. ${ }^{90}$ These studies open mechanisms to develop nanosuspensionbased phytoconstituents for antidiabetic activity in various animal models.

\section{PLGA NPs}

Polylactic-co-glycolic acid nanoparticles (PLGA NPs act as an effective carrier in oral delivery systems for various phytobioactive compounds due to the effective bioavailability and stability of those compounds. ${ }^{91}$ Antidiabetic phyto compounds, such as quercetin and curcumin, are effectively entrapped or absorbed in PLGA nanoparticles with a size $<100 \mathrm{~nm}$ using various methods, such as solvent evaporation or nanoprecipitation, and these novel delivery systems have shown improved antidiabetic effects. ${ }^{92,93}$ Recently, quercetin-loaded PLGA NPs were studied for their efficacy in the diabetic model. Quercetin-loaded PLGA NPs were prepared with a particle size of $\sim 179 \mathrm{~nm}$, with a uniform particle size and smooth appearance. An animal study showed that the effect of the PLGA NPs every 5 days through oral delivery is equivalent to an everyday dosage of control quercetin. This study confirmed that PLGA NPs are very effective in delivering quercetin, thereby limiting the need for everyday dosage and reducing the frequency of taking the drug. ${ }^{94}$ PLGA NPs loaded with fenugreek seed extract showed a higher antidiabetic efficacy in the alloxan-induced diabetic model ${ }^{95}$ with a higher antioxidant and antilipid peroxidation activity. Thymoquinone from black seeds has potent antidiabetic efficacy and was studied to develop thymoquinone-loaded PLGA NPs, which showed an enhanced antioxidative effect along with sustained release in simulated gastrointestinal systems. ${ }^{96}$ Costus speciosus extract-loaded PLGA NPs were also studied for their efficacy in the antidiabetic model, and the study confirmed that costus speciosus extract-loaded PLGA NPs can effectively control glucose..$^{97}$

\section{Nano phytobioactive compounds used in the treatment of T2DM}

Nanoscale phyto-derived bioactive compounds or phyto extracts showed improved bioavailability in many chronic diseases, including T2DM. Nanoscale processing improves the efficaciy of these compounds through higher exposure of the active sites, thereby improving the bioactivity. ${ }^{98}$ Furthermore nanodelivery systems can overcome many barriers in gastrointestinal systems, thereby improving the bioavailability to various target sites and preventing oxidative stress-related disease along with chronic disease, including T2DM. A few nano-phytobioactive compounds with improved bioactivity are discussed in this section.

\section{Nano-silibinin}

Silibinin is a major bioactive compounds in milk thistle, and it has shown higher antidiabetic activities in various cell and animal models. ${ }^{99-103}$ Many animal models have shown that a higher consumption of those compounds results in improved antidiabetic activities along with the neuropathy and nephropathy. Although these compounds have shown antidiabetic activities with higher potential, their systematic bioavailability and absorption in the stomach and intestine are relatively low. ${ }^{104-106}$ Recently, various nanodelivery approaches have been studied to improve their bioavailability in diabetic animal models, and this could be a novel approach to silibinin-based nano treatment of T2DM. PLGA-loaded silibinin NPs were studied for their antidiabetic activities in streptozotocin-induced diabetes rat models. The silibinin-loaded NPs with a size of $\sim 230 \mathrm{~nm}$ showed an improved bioavailability of such compounds in the systematic circulation along with a higher restoration of the pancreatic cells. The study also confirmed that higher 
antidiabetic activities of silibinin-loaded NPs were most likely due to a higher passive transport and restoration of the antioxidative status. ${ }^{107}$ Similarly, silibinin-loaded nanoliposomes showed improved bioavailability in other chronic disease models. In another study, silibinin-coloaded with another glycyrrhizic acid-loaded nanoliposome showed improved stability and bioactivity in cell models. ${ }^{108}$ These studies have shown that nanodelivery systems can improve the availability and therapeutic nature of bioactive compounds to manage diabetes.

\section{Nano-quercetin}

Quercetin is another phytobioactive compound, and it has shown potential bioactivity against various oxidative stress-related diseases, including T2DM. ${ }^{109-113}$ Although quercetin shows beneficial activities in various cell and animal antidiabetes study models, its efficacy through oral delivery systems is very low due to the postabsorptive metabolism and gastrointestinal conditions. ${ }^{114-117}$ Several approaches have been carried out to improve the bioavailability of quercetin in order to improve its bioactivity. The nanodelivery approach is quite promising in the delivery of the quercetin through oral intake, thereby enhancing its antidiabetic activities. Recently, PLGA-loaded quercetin NPs were developed with a particle size of $\sim 179 \mathrm{~nm}$, showing improved bioavailability in a streptozotocin-induced diabetic rat model. This study confirmed that in spite of reduced dosage and dosing times, the antidiabetic potential of the quercetin can be improved by using PLGA delivery systems. ${ }^{94}$ Few other nanodelivery approaches have also been developed to improve the bioavailability of quercetin for other chronic diseases, including brain bioavailability. Quercetin nanorods were recently developed and characterized, showing improved antidiabetic activity along with certain organ functions restored. ${ }^{116}$ This has further confirmed that nanodelivery systems can improve the bioavailability of such compounds in various organs.

A few studies have compared various delivery methods in terms of the efficacy of quercetin delivery, such as solid lipid NPs, NLC, and nanoemulsions, systems for quercetin indicate that NLC has improved the bioaccessibility of quercetin in an in vitro model. Furthermore, this opens up many research avenues to conduct quercetin-based nanocarrier development to improve oral delivery of these compounds with a lower dose and enhanced protectivity. This can limit the drug loading efficiency to patients and will be developed as a future medicine with lower carrier toxicity to diabetic patients.

\section{Nano-baicalin}

Baicalin is a novel antidiabetic bioactive compound that is found specifically in certain plants, namely scutellaria, and it has potential bioactivity against T2DM. ${ }^{118-123}$ These bioactive compound are highly hydrophobic, which limits their bioavailability through oral delivery systems and in turn limits their functional activity. Many novel delivery approaches have been developed to improve its bioavailability. ${ }^{124,125}$ Recently, a nano-based delivery approach was carried out to improve the bioavailability by using a NLC delivery system. A baicalin-loaded nano-lipid carrier delivery system was developed with a uniform particle size of $\sim 92 \mathrm{~nm}$, and it showed higher antidiabetic activity than conventional baicalin, which in turn will limit the drug dosage levels. ${ }^{17}$ Similarly, another approach was done to improve the bioavailability of those compounds through NLC systems with a particle size of $\sim 244 \mathrm{~nm}$, which showed a sustained release of the bioactive compound with improved activity. ${ }^{59}$ A baicalin nanoemulsion was also studied for its bioavailability through oral delivery. Baicalin-loaded nanoemulsion showed a 7 times increase in bioavailability than the free suspension, which could be useful for various treatments including T2DM. The storage stability of the baicalinloaded nanoemulsion was also studied for 6 months, and the results showed greater stability with a uniform particle size. ${ }^{126}$ In another study, baicalin-loaded nanoliposome with a particle size of $\sim 375 \mathrm{~nm}$ showed a higher bioavailability in many target organs, including kidney, liver, and pancreas. ${ }^{127}$ Various nanodelivery approaches show that baicalin can be successfully delivered using novel oral delivery systems in the future to treat chronic diseases, including T2DM.

\section{Nano-curcumin}

For centuries, curcumin has been used in food and medicine Asia due to its efficacy against T2DM. ${ }^{128-131}$ However, it has low potential through oral delivery due to the low water solubility and stability in gastrointestinal environment. ${ }^{132-136}$ Nanodelivery systems are an alternative approach that can improve the stability of those compounds with improved bioavailability of curcumin. ${ }^{137-150}$ Curcumin-loaded PLGA NPs were constructed with a particle size of $281 \mathrm{~nm}$, and these have shown a higher bioavailability through oral delivery in the diabetic rat model, delaying cataracts. ${ }^{151}$ The self-nanoemulsifying curcumin delivery system was developed, has a particle size of $\sim 213 \mathrm{~nm}$, and has shown improved protection of diabetic neuropathy through oral delivery systems in male Sprague Dawley rats. ${ }^{152}$ Several other nanodelivery systems have shown a higher bioavailability for curcumin, delaying 
the progression of T2DM. Recently, a curcumin-loaded food grade nanoemulsion for oral delivery developed with a particle size of $110 \mathrm{~nm}$ showed a higher bioavailability at lower dosage levels. ${ }^{153}$ In another study, curcumin-loaded PLGA NP was prepared for oral delivery with a particle size of $\sim 158 \mathrm{~nm}$, and it showed enhanced solubility and bioavailability. The oral bioavailability of nano-formulated curcumin showed a 22 times increase over conventional curcumin. ${ }^{154}$ Curcumin nano-micelles were also constructed for oral delivery with a particle size of $\sim 17 \mathrm{~nm}$, and these showed a 2 times increase in bioavailability. ${ }^{155}$ Nevertheless, further research is necessary to assess the efficacy of the highly bioavailable nano-curcumin in T2DM.

\section{Nano-emodin}

Emodin is a novel natural antidiabetic compound that is found in many herbs, including Japanese knotweed, buckthorn, and rhubarb, and it has an effective therapeutic effect in diabetesassociated diseases. ${ }^{156-162}$ Emodin also plays an active role in treating diabetic nephropathy and neuropathy at earlier stages. However, due to the high first pass metabolism and greater hydrophobicity of emodin, it cannot be efficiently delivered through oral means, limiting the bioavailability and bioaccessibility of the compound. ${ }^{163-169}$ A novel delivery approach was carried out using various delivery technologies, including nanoemulsions and nanotransfers, and some showed efficient delivery of emodin through oral means, which in turn enhances its efficacy. Recently, emodin-loaded magnesium hollow silicate nanocarriers were studied for their efficacy in treating angiogenesis associated with diabetic retinopathy. The NPs, with an average mean size of $\sim 400 \mathrm{~nm}$, showed higher efficacy in delivery and greater protective characteristics against angiogenesis. ${ }^{170}$ Emodin-loaded nano-transferosome was also studied against obesity, a causative factor for T2DM. The size of emodin loaded nano-transferosome was of $\sim 292 \mathrm{~nm}$ with encapsulation efficacy of $\sim 69 \%$, and these showed a relatively higher effect in terms of antiobesity activity, ${ }^{171}$ which is an alternative approach to reduce the risk for T2DM. A few other nanodelivery approaches have also been conducted to improve the oral stability of emodin-like nanoemulsion. The emodin-loaded nanoemulsion was constructed with a particle size of $\sim 10-30 \mathrm{~nm}$, and it showed sustained release in vitro, which could be a possible alternative delivery approach for a functional compound, such as emodin. ${ }^{172}$ The same research group also studied the bioavailability of an emodin-loaded nanoemulsion in rats. The distribution of nano emodin was found to be higher in the liver and lung, whereas lower in the brain with a higher mean resident time. ${ }^{173}$ The above approach can be used for nanodelivery systems to improve the bioavailability of emodin in various target organs, thereby enhancing its bioactivity against chronic disease, such as T2DM.

\section{Nano-naringenin}

Naringenin is a flavonoid compound that is present in many citrus fruits and their related beverages, and it has shown a high antidiabetic potential in many cellular and animal models. ${ }^{174-180}$ Due to their higher potential activity in many chronic diseases, they are widely used to prepare novel beverages. However, due to the limited oral bioavailability and stability of those compounds, alternative nano-based delivery technologies have been recently studied to assess their efficacy. ${ }^{181-185}$ A naringenin-based nanoemulsion was developed with a particle size of $\sim 50 \mathrm{~nm}$, showing the enhanced bioavailability of naringenin through oral delivery. The enhanced bioavailability of naringenin was most likely due to its higher solubility through self-emulsion nanodelivery systems, which can improve its therapeutic application. ${ }^{186}$ Naringenin-loaded NPs were prepared with a mean particle size of $\sim 66 \mathrm{~nm}$, and these showed a higher bioavailability through oral delivery, thereby improving its hepatoprotective activity in rat models. ${ }^{187}$ Similarly, naringenin-loaded solid lipid NPs were constructed with particle sizes ranging from $\sim 60$ to $80 \mathrm{~nm}$, and these showed a higher cellular uptake. ${ }^{188}$ In another study, naringenin-loaded chitosan nanoparticles were constructed with a particle size of $\sim 407 \mathrm{~nm}$, and these showed higher encapsulation efficiency of $\sim 70 \%$ with improved antioxidant activity for in vitro cell models. ${ }^{184}$ Although many nanodelivery approaches were accessed for their oral bioavailability potential in various related disease models, their potential for T2DM animal model and its related diseases is still limited.

\section{Nano-morin}

Morin is a phyto-derived bioflavonoid seen in many fruits, vegetables, and herbs, and it has shown multiple potential activities against diabetes and its associated diseases. ${ }^{189-193}$ Its potential activities include reducing lipogenesis, oxidative stress, gluconeogenesis, and inflammation. A higher hepatoprotective activity was also reported for morin in certain studies, which indicated it can reduce hyperlipidemia. In addition, morin has an insulin-mimetic effect, and it is widely accepted to be a naturally derived antidiabetic drug. ${ }^{194,195}$ Due to its poor oral solubility, its bioavailability is limited, resulting in lower effects. However, an increased 
dosage may result in toxicity. To overcome such disadvantages, novel nanodelivery approaches have been studied to improve its bioavailability through oral delivery. ${ }^{196-198}$ Recently, morin-loaded self-nanoemulsifying nanodelivery systems were developed and studied for their oral bioavailability. The improved oral bioavailability of these compounds was observed to lead to an improved bioactivity to treat many chronic diseases. ${ }^{197}$ In another approach, morin was successfully formulated using mixed micelles with a particle size of $\sim 90 \mathrm{~nm}$. The nanosized morin-loaded mixed micelles showed a 3.6 times increase in cellular uptake compared to native compounds, with a higher permeability rate of by $\sim 2.4$ times, which in turn improves the bioavailability in systematic circulation. ${ }^{199}$ In another approach, morin-loaded solid lipid nanoparticles were studied for their efficacy in the oral bioavailability, confirming that a lower particle size improves the permeability of the compound through an intestine membrane with a prolonged release of the compound. ${ }^{200}$ Many successful, nanoscale techniques have been used to improve the bioavailability of morin during oral delivery; this helps researchers to study their potential in chronic disease models, includes type 2 diabetes and its associated diseases.

\section{Nano-genistein}

Genistein is a soy isoflavonoid with potential antidiabetic activities through various actions, including antioxidant activity, glucose-stimulated insulin secretion, estrogen receptor agonist, and $\beta$-cell proliferation at various concentration levels. ${ }^{201-207}$ Regular consumption of genisteinrich foods has shown improved beneficial activities in many chronic diseases. Soy isoflavone-incorporated health drinks are permitted in the US for their improved beneficial actions. ${ }^{208,209}$ However, the lower solubility and loss of bioactivity through oral delivery has led to less bioavailability of genistein in various animal studies. In addition, a higher dosage leads to other complications and toxicity. ${ }^{209,210}$ In recent years, a few nanoscale techniques have been implemented to overcome the toxicity and higher dosage effects, improving the oral delivery of genistein. ${ }^{211-213}$ Genisteinloaded polymeric micelles showed a higher bioavailability for genistein through oral delivery, with a particle size of $\sim 27.76 \mathrm{~nm}$. The bioavailability of the genistein micelles was greatly improved through oral delivery, and it was most likely due to the higher solubility of the compound and improved permeability. ${ }^{214}$ In another approach, the oral delivery of genistein was successfully improved through self-emulsifying phospholipid preconcentrates of genistein with sizes ranging from 165 to $425 \mathrm{~nm}$, showing a higher permeability rate of $\sim 12 \%$, which in turn improved the bioactivity. ${ }^{215}$ An alternative approach co-loading two natural bioactive compounds, such as curcumin and genistein, was studied in an NLC delivery system, and it showed significant activity with higher stability and solubility of each compound. Although many approaches have been carried out to improve the bioavailability of genistein in many chronic diseases, but the applicability to type 2 diabetes mellitus animal model is still limited.

\section{Nano-hesperidin}

Hesperidin is another phyto-derived flavonoid compound that possesses multiple antidiabetic activities through controlled glucose and lipid levels along with higher antioxidant activities, thereby reducing the cellular damage and insulin resistance levels. ${ }^{216-220}$ This compound is highly bioavailable in lemon fruits and their juices. The lower bioavailability of those compounds through oral delivery leads to lower beneficial effects at higher doses. ${ }^{221-223}$ Many nanotechnological approaches have been carried out to improve their bioavailability, thereby improving the beneficial antidiabetic effects of those compounds. Hesperidin nanocrystals were prepared with a particle size of $3.96 \mathrm{~nm}$, and these showed an improved stability that could be useful in many functional applications. ${ }^{224,225}$ In another approach, hesperidin-loaded solid lipid nanoparticles and NLCs were successfully developed with a lower particle size, and these showed improved stability in functional food that could be useful to treat various diseases through their functional activities. ${ }^{224}$ Furthermore, hesperetin-loaded NPs with a particle size of $\sim 55-180 \mathrm{~nm}$ were also studied for their efficacy in sustained release of the compound. ${ }^{226}$ The in vitro cell study showed that hesperetin had sustained release of the compound with a higher antioxidant activity.

\section{Nano-daidzein}

Daidzein is another potential antidiabetic compound from soy-based food products, and in various animal studies, it exerted its antidiabetic activity by enhancing the glucose and lipid metabolism. ${ }^{227-234}$ Due to their limited bioavailability through high hydrophobicity, nanolipid carrier-based technologies have been recently used to improve the bioavailability for oral delivery. A lipid-based nanodelivery approach was recently developed to improve the effect of daidzein through oral delivery, and the daidzein-loaded lipid carrier was found to have a 6.8 times increase in bioavailability. ${ }^{235}$ In another approach, a daidzein-loaded self-assembly 
nanodelivery system showed higher bioavailability than in free suspension. ${ }^{236}$ The above research shows that potential antidiabetic compounds with lower gastric bioavailability can be successfully delivered orally by using lipid-based nanodelivery systems.

\section{Conclusion}

In this review, we have discussed various food grade nanodelivery systems to effectively deliver antidiabetic compounds with a much more novel approach in treating T2DM. This has been used to overcome many complications in traditional treatment of phyto-derived bioactive compounds with a lower potential antidiabetic effect due to the lower stability of those compounds in gastrointestinal systems and during absorption. Phyto-derived bioactive compounds have been loaded into nanoparticles for oral delivery in various antidiabetic animal models, and the results have shown improved stability, bioavailability, and sustained antidiabetic effects. Certain studies confirm that the coadministration of two or more antidiabetic compounds through nanodelivery systems lowers the drug load and provides improved beneficial activities, without altering the stability and bioaccessibility between those compounds. In addition, most carriers used in the delivery of phyto-based bioactive compounds are highly biodegradable because they contain natural materials, and this can reduce the toxicity of the carrier systems. Several phytobioactive compounds loaded into nanodelivery systems are currently in clinical trials, and once these compounds are commercially marketed, nano phyto-based bioactive compounds will be available as novel medicines to treat many chronic diseases, including T2DM. This review confirms that most phyto-derived antidiabetic compounds can be successfully formulated using various nanodelivery approaches to improve the efficacy and provide sustained beneficial effects.

\section{Acknowledgment}

This work was supported by the National Research Foundation of Korea (NRF) grant funded by the Korean government (MEST) (No 2014R1A2A2A04007791).

\section{Disclosure}

The authors report no conflicts of interest in this work.

\section{References}

1. Nathan DM. Diabetes: advances in diagnosis and treatment. JAMA. 2015;314(10):1052-1062

2. Wu YL, Ding YP, Tanaka Y, Zhang W. Risk factors contributing to type 2 diabetes and recent advances in the treatment and prevention. Int $J$ Med Sci. 2014;11(11):1185-1200.
3. Nerurkar PV, Hwang PW, Saksa E. Anti-diabetic potential of noni: the Yin and the Yang. Molecules. 2015;20(10):17684-17719.

4. Rana S, Kumar S, Rathore N, Padwad Y, Bhushan S. Nutrigenomics and its impact on life style associated metabolic diseases. Curr Genomics. 2016; 17(3):261-278.

5. Gothai S, Ganesan P, Park SY, Fakurazi S, Choi DK, Arulselvan P. Natural phyto-bioactive compounds for the treatment of type 2 diabetes: inflammation as a target. Nutrients. 2016;8(8). pii: E461.

6. Vaithiyanathan V, Mirunalini S. Quantitative variation of bioactive phyto compounds in ethyl acetate and methanol extracts of Pergularia daemia (Forsk.) Chiov. J Biomed Res. 2015;29(2): 169-172.

7. Arulselvan P, Senthilkumar GP, Sathish Kumar D, Subramanian S Anti-diabetic effect of Murraya koenigii leaves on streptozotocin induced diabetic rats. Die Pharmazie. 2006;61(10):874-877.

8. Arulselvan P, Subramanian SP. Beneficial effects of Murraya koenigii leaves on antioxidant defense system and ultra structural changes of pancreatic beta-cells in experimental diabetes in rats. Chem Biol Interact. 2007;165(2):155-164.

9. Behera KK, Paul TV, Arulselvan S, Varghese AM. Visual vignette. Endocr Prac. 2008;14(9):1191.

10. Muhammad AA, Arulselvan P, Cheah PS, Abas F, Fakurazi S. Evaluation of wound healing properties of bioactive aqueous fraction from Moringa oleifera Lam on experimentally induced diabetic animal model. Drug Des Devel Ther. 2016;10:1715-1730.

11. Rajasekaran S, Sriram N, Arulselvan P, Subramanian S. Effect of aloe vera leaf gel extract on membrane bound phosphatases and lysosomal hydrolases in rats with streptozotocin diabetes. Pharmazie. 2007;62(3): 221-225.

12. Sellamuthu PS, Arulselvan P, Fakurazi S, Kandasamy M. Beneficial effects of mangiferin isolated from Salacia chinensis on biochemical and hematological parameters in rats with streptozotocin-induced diabetes. Pak J Pharm Sci. 2014;27(1):161-167.

13. Sellamuthu PS, Arulselvan P, Kamalraj S, Fakurazi S, Kandasamy M. Protective nature of mangiferin on oxidative stress and antioxidant status in tissues of streptozotocin-induced diabetic rats. ISRN Pharmacol. 2013;2013:750109.

14. Sellamuthu PS, Arulselvan P, Muniappan BP, Fakurazi S, Kandasamy M. Mangiferin from Salacia chinensis prevents oxidative stress and protects pancreatic beta-cells in streptozotocin-induced diabetic rats. $J$ Med Food. 2013;16(8):719-727.

15. Syarina PN, Karthivashan G, Abas F, Arulselvan P, Fakurazi S. Wound healing potential of Spirulina platensis extracts on human dermal fibroblast cells. EXCLI J. 2015;14:385-393.

16. Hatanaka J, Chikamori H, Sato H, et al. Physicochemical and pharmacological characterization of alpha-tocopherol-loaded nano-emulsion system. Int J Pharm. 2010;396(1-2):188-193.

17. Shi F, Wei Z, Zhao Y, Xu X. Nanostructured lipid carriers loaded with baicalin: an efficient carrier for enhanced antidiabetic effects Pharmacogn Mag. 2016;12(47):198-202.

18. Yadav SC, Yadav SK, Sood A, Sharma M, Singh B. Development of antidiabetic nanomedicine from stevioside. J Biomed Nanotechnol. 2011;7(1): $54-55$.

19. Thambi T, Park JH, Lee DS. Stimuli-responsive polymersomes for cancer therapy. Biomater Sci. 2016;4(1):55-69.

20. Sim HJ, Thambi T, Lee DS. Heparin-based temperature-sensitive injectable hydrogels for protein delivery. J Mater Chem B. 2015;3(45): 8892-8901.

21. Sharma HS, Feng LY, Lafuente JV, et al. TiO2-Nanowired delivery of mesenchymal stem cells thwarts diabetes-induced exacerbation of brain pathology in heat stroke: an experimental study in the rat using morphological and biochemical approaches. CNS Neurol Disord-Dr. 2015;14(3):386-399.

22. Sharma HS, Sharma A. Nanowired drug delivery for neuroprotection in central nervous system injuries: modulation by environmental temperature, intoxication of nanoparticles, and comorbidity factors. Wiley Interdiscip Rev Nanomed Nanobiotechnol. 2012;4(2):184-203. 
23. Tian ZR, Sharma A, Nozari A, Subramaniam R, Lundstedt T, Sharma HS. Nanowired drug delivery to enhance neuroprotection in spinal cord injury. CNS Neurol Disord Drug Targets. 2012;11(1):86-95.

24. Kar A, Mukherjee PK, Saha S, Bahadur S, Ahnuned SKM, Pandit S. Possible herb-drug interaction of Morus alba L. - a potential anti-diabetic plant from Indian Traditional medicine. Indian J Tradit Know. 2015;14(4): 626-631.

25. Agnaniet $\mathrm{H}$, Mbot EJ, Keita O, et al. Antidiabetic potential of two medicinal plants used in Gabonese folk medicine. BMC Complement Altern Med. 2016;16:71.

26. Cheng SH, Barakatun-Nisak MY, Anthony J, Ismail A. Potential medicinal benefits of Cosmos caudatus (Ulam Raja): a scoping review. J Res Med Sci. 2015;20(10):1000-1006.

27. El Awdan SA, Abdel Jaleel GA, Saleh DO, et al. Hypoglycemic activity of Gleditsia caspica extract and its saponin-containing fraction in streptozotocin-induced diabetic rats. Z Naturforsch C. 2016;71(7-8): 253-260.

28. Guo J, Tao H, Cao Y, Ho CT, Jin S, Huang Q. Prevention of obesity and type 2 diabetes with aged citrus peel (Chenpi) extract. J Agric Food Chem. 2016;64(10):2053-2061.

29. Kittl M, Beyreis M, Tumurkhuu M, et al. Quercetin stimulates insulin secretion and reduces the viability of rat INS-1 beta-cells. Cell Physiol Biochem. 2016;39(1):278-293.

30. Salemi Z, Barzin Tond S, Fallah S, Shojaii A, Seifi M. The effect of Morus alba leaves extract and powder on resistin levels and liver transaminase enzymes activities in diabetes. Cell Mol Biol (Noisy-le-grand). 2016; 62(6):112-118.

31. Seo YS, Shon MY, Kong R, et al. Black ginseng extract exerts antihyperglycemic effect via modulation of glucose metabolism in liver and muscle. J Ethnopharmacol. 2016;190:231-240.

32. Kumar B, Singh V, Shankar R, Kumar K, Rawal RK. Synthetic and medicinal prospective of structurally modified curcumins. Curr Top Med Chem. Epub 2016 Jun 4

33. Parmar MS, Syed I, Gray JP, Ray SD. Curcumin, hesperidin, and rutin selectively interfere with apoptosis signaling and attenuate streptozotocin-induced oxidative stress-mediated hyperglycemia. Curr Neurovasc Res. 2015;12(4):363-374.

34. Rashid K, Sil PC. Curcumin enhances recovery of pancreatic islets from cellular stress induced inflammation and apoptosis in diabetic rats. Toxicol Appl Pharmacol. 2015;282(3):297-310.

35. Zhang F, Yang F, Zhao H, An Y. Curcumin alleviates lung injury in diabetic rats by inhibiting NF-kB pathway. Clin Exp Pharmacol Physiol. Epub 2015 Jun 26.

36. Hazarika R, Parida P, Neog B, Yadav RN. Binding Energy calculation of GSK-3 protein of Human against some anti-diabetic compounds of Momordica charantia linn (Bitter melon). Bioinformation. 2012;8(6): 251-254.

37. Leung L, Birtwhistle R, Kotecha J, Hannah S, Cuthbertson S. Antidiabetic and hypoglycaemic effects of Momordica charantia (bitter melon): a mini review. Br J Nutr. 2009;102(12):1703-1708.

38. Salvia-Trujillo L, Martin-Belloso O, McClements DJ. Excipient nanoemulsions for improving oral bioavailability of bioactives. Nanomaterials. 2016;6(1):17.

39. Salvia-Trujillo L, McClements DJ. Improvement of beta-carotene bioaccessibility from dietary supplements using excipient nanoemulsions. J Agr Food Chem. 2016;64(22):4639-4647.

40. Zou LQ, Zheng BJ, Zhang RJ, et al. Food matrix effects on nutraceutical bioavailability: impact of protein on curcumin bioaccessibility and transformation in nanoemulsion delivery systems and excipient nanoemulsions. Food Biophys. 2016;11(2):142-153.

41. Chen X, Zou LQ, Niu J, Liu W, Peng SF, Liu CM. The stability, sustained release and cellular antioxidant activity of curcumin nanoliposomes. Molecules. 2015;20(8):14293-14311.

42. Zou LQ, Zheng BJ, Zhang RJ, et al. Enhancing the bioaccessibility of hydrophobic bioactive agents using mixed colloidal dispersions: curcumin-loaded zein nanoparticles plus digestible lipid nanoparticles. Food Res Int. 2016;81:74-82.
43. Liu X, Bi JF, Xiao H, McClements DJ. Enhancement of nutraceutical bioavailability using excipient nanoemulsions: role of lipid digestion products on bioaccessibility of carotenoids and phenolics from mangoes. J Food Sci. 2016;81(3):N754-N761.

44. Salvia-Trujillo L, McClements DJ. Enhancement of lycopene bioaccessibility from tomato juice using excipient emulsions: influence of lipid droplet size. Food Chem. 2016;210:295-304.

45. Zhang RJ, Zhang ZP, Zou LQ, et al. Enhancement of carotenoid bioaccessibility from carrots using excipient emulsions: influence of particle size of digestible lipid droplets. Food Funct. 2016;7(1):93-103.

46. Aldawsari HM, Hanafy A, Labib GS, Badr JM. Antihyperglycemic activities of extracts of the mistletoes plicosepalus acaciae and P-curviflorus in comparison to their solid lipid nanoparticle suspension formulations. Z Naturforsch C. 2014;69(9-10):391-398.

47. Bouttefeux O, Beloqui A, Preat V. Delivery of peptides via the oral route: diabetes treatment by peptide-loaded nanoparticles. Curr Pharm Des. 2016;22(9):1161-1176.

48. Goncalves LM, Maestrelli F, Di Cesare Manelli L, Ghelardini C, Almeida AJ, Mura P. Development of solid lipid nanoparticles as carriers for improving oral bioavailability of glibenclamide. Eur J Pharm Biopharm. 2016;102:41-50.

49. Sharma G, Sharma AR, Nam JS, Doss GPC, Lee SS, Chakraborty C. Nanoparticle based insulin delivery system: the next generation efficient therapy for Type 1 diabetes. J Nanobiotechnology. 2015;13:74.

50. Soudry-Kochavi L, Naraykin N, Nassar T, Benita S. Improved oral absorption of exenatide using an original nanoencapsulation and microencapsulation approach. J Control Release. 2015;217: 202-210.

51. Xue M, Yang MX, Zhang W, et al. Characterization, pharmacokinetics, and hypoglycemic effect of berberine loaded solid lipid nanoparticles. Int J Nanomedicine. 2013;8:4677-4687.

52. Xue M, Zhang L, Yang MX, et al. Berberine-loaded solid lipid nanoparticles are concentrated in the liver and ameliorate hepatosteatosis in $\mathrm{db} / \mathrm{db}$ mice. Int J Nanomed. 2015;10:5049-5057.

53. Wang ZP, Li Y, Zhou Q, Wang YF, Chen TS. Berberine-loaded solid lipid nanoparticles enhance hypoglycemic efficacy on streptozotocininduced diabetic C57BL/6 mice. Nanomed-Nanotechnol. 2016;12(2): 483-484.

54. Ni SL, Sun R, Zhao GD, Xia Q. Quercetin loaded nanostructured lipid carrier for food fortification: preparation, characterization and in vitro study. J Food Process Eng. 2015;38(1):93-106.

55. Elmowafy M, Samy A, Raslan MA, et al. Enhancement of bioavailability and pharmacodynamic effects of thymoquinone via nanostructured lipid carrier (NLC) formulation. AAPS PharmSciTech. 2016;17(3): 663-672.

56. Liu GY, Wang JM, Xia Q. Application of nanostructured lipid carrier in food for the improved bioavailability. Eur Food Res Technol. 2012;234(3): 391-398.

57. Okonogi S, Riangjanapatee P. Physicochemical characterization of lycopene-loaded nanostructured lipid carrier formulations for topical administration. Int J Pharmaceut. 2015;478(2):726-735.

58. Shin GH, Kim JT, Park HJ. Recent developments in nanoformulations of lipophilic functional foods. Trends Food Sci Tech. 2015;46(1): 144-157.

59. Luan JJ, Zheng F, Yang XY, Yu AH, Zhai GX. Nanostructured lipid carriers for oral delivery of baicalin: in vitro and in vivo evaluation. Colloid Surface A. 2015;466:154-159.

60. Sun M, Nie S, Pan X, Zhang R, Fan Z, Wang S. Quercetin-nanostructured lipid carriers: characteristics and anti-breast cancer activities in vitro. Colloids Surfaces B Biointerfaces. 2014;113:15-24.

61. Aditya NP, Macedo AS, Doktorovov S, et al. Development and evaluation of lipid nanocarriers for quercetin delivery: a comparative study of solid lipid nanoparticles (SLN), nanostructured lipid carriers (NLC), and lipid nanoemulsions (LNE). LWT-Food Sci Technol. 2014;59(1):115-121.

62. Liu L, Tang YH, Gao C, et al. Characterization and biodistribution in vivo of quercetin-loaded cationic nanostructured lipid carriers. Colloid Surface B Biointerfaces. 2014;115:125-131. 
63. Allam AN, Komeil IA, Fouda MA, Abdallah OY. Preparation, characterization and in vivo evaluation of curcumin self-nano phospholipid dispersion as an approach to enhance oral bioavailability. Int J Pharmaceut. 2015;489(1-2):117-123.

64. Zhongfa L, Chiu M, Wang J, et al. Enhancement of curcumin oral absorption and pharmacokinetics of curcuminoids and curcumin metabolites in mice. Cancer Chemother Pharmacol. 2012;69(3):679-689.

65. Sankar P, Telang AG, Ramya K, Vijayakaran K, Kesavan M, Sarkar SN. Protective action of curcumin and nano-curcumin against arsenic-induced genotoxicity in rats in vivo. Mol Biol Rep. 2014;41(11):7413-7422.

66. Young NA, Bruss MS, Gardner M, et al. Oral administration of nanoemulsion curcumin in mice suppresses inflammatory-induced NFkB signaling and macrophage migration. PLoS One. 2014;9(11):e111559.

67. Paul D, Dey TK, Mukherjee S, Ghosh M, Dhar P. Comparative prophylactic effects of alpha-eleostearic acid rich nano and conventional emulsions in induced diabetic rats. J Food Sci Technol. 2014;51(9): 1724-1736.

68. Paul D, Mukherjee S, Chakraborty R, Mallick SK, Dhar P. Comparative real-time study of cellular uptake of a formulated conjugated linolenic acid rich nano and conventional macro emulsions and their bioactivity in ex vivo models for parenteral applications. Colloid Surface B Biointerfaces. 2015;126:426-436.

69. Sankar P, Telang AG, Kalaivanan R, Karunakaran V, Manikam K, Sarkar SN. Effects of nanoparticle-encapsulated curcumin on arsenicinduced liver toxicity in rats. Environ Toxicol. 2015;30(6):628-637.

70. Dora CL, Silva LFC, Mazzarino L, et al. Oral delivery of a high quercetin payload nanosized emulsion: in vitro and in vivo activity against B16-F10 melanoma. J Nanosci Nanotechno. 2016;16(2): 1275-1281.

71. Hadrich G, Vaz GR, Maidana M, et al. Anti-inflammatory effect and toxicology analysis of oral delivery quercetin nanosized emulsion in rats. Pharm Res. 2016;33(4):983-993.

72. Gothwal A, Khan I, Gupta U. Polymeric micelles: recent advancements in the delivery of anticancer drugs. Pharm Res. 2016;33(1):18-39.

73. Kaiser JM, Imai H, Haakenson JK, et al. Nanoliposomal minocycline for ocular drug delivery. Nanomedicine. 2013;9(1):130-140.

74. Liu J, Chen S, Lv L, Song L, Guo S, Huang S. Recent progress in studying curcumin and its nano-preparations for cancer therapy. Curr Pharm Des. 2013;19(11):1974-1993.

75. McClements DJ. Design of nano-laminated coatings to control bioavailability of lipophilic food components. J Food Sci. 2010;75(1): R30-R42.

76. Watal G, Watal A, Rai PK, Rai DK, Sharma G, Sharma B. Biomedical applications of nano-antioxidant. Methods Mol Biol.2013; 1028:147-151.

77. Gunasekaran T, Haile T, Nigusse T, Dhanaraju MD. Nanotechnology: an effective tool for enhancing bioavailability and bioactivity of phytomedicine. Asian Pac J Trop Biomed. 2014;4(Suppl 1):S1-S7.

78. Aisha AFA, Majid AMSA, Ismail Z. Preparation and characterization of nano liposomes of Orthosiphon stamineus ethanolic extract in soybean phospholipids. BMC Biotechnol. 2014;14:23.

79. Basavaraj S, Betageri GV. Improved oral delivery of resveratrol using proliposomal formulation: investigation of various factors contributing to prolonged absorption of unmetabolized resveratrol. Expert Opin Drug Deliv. 2014;11(4):493-503.

80. Rashidinejad A, Birch EJ, Everett DW. A novel functional full-fat hard cheese containing liposomal nanoencapsulated green tea catechins: manufacture and recovery following simulated digestion. Food Funct. 2016;7(7):3283-3294.

81. Agrawal AK, Harde H, Thanki K, Jain S. Improved stability and antidiabetic potential of insulin containing folic acid functionalized polymer stabilized multi layered liposomes following oral administration. Biomacromolecules. 2014;15(1):350-360.

82. Du J, Li XG, Zhao HX, et al. Nanosuspensions of poorly watersoluble drugs prepared by bottom-up technologies. Int $J$ Pharmaceut. 2015;495(2):738-749.
83. Liu T, Muller RH, Moschwitzer JP. Effect of drug physico-chemical properties on the efficiency of top-down process and characterization of nanosuspension. Expert Opin Drug Deliv. 2015;12(11):1741-1754.

84. Yadollahi R, Vasilev K, Simovic S. Nanosuspension technologies for delivery of poorly soluble drugs. J Nanomater. 2015;2015:1.

85. Zhang X, Li LC, Mao S. Nanosuspensions of poorly water soluble drugs prepared by top-down technologies. Curr Pharm Des. 2014;20(3): 388-407.

86. Ravichandran R. Formulation of nanosuspensions of gymnemic acids for oral administration. Int J Nanoparticles. 2010;3(4):309.

87. Wang ZP, Wu JB, Zhou Q, Wang YF, Chen TS. 1 Berberine nanosuspension enhances hypoglycemic efficacy on streptozotocin induced diabetic C57BL/6 mice. Evid Based Complement Alternat Med. 2015;2015:239749.

88. Ravichandran R. Studies on gymnemic acids nanoparticulate formulations against diabetes mellitus. Int J Biomed Clin Eng. 2012;1(2):1-12.

89. Sun M, Gao Y, Pei Y, et al. Development of nanosuspension formulation for oral delivery of quercetin. J Biomed Nanotechnol. 2010;6(4): 325-332.

90. Gao Y, Wang C, Sun M, et al. In vivo evaluation of curcumin loaded nanosuspensions by oral administration. J Biomed Nanotechnol. 2012; 8(4):659-668.

91. Chakraborty S, Stalin S, Das N, Choudhury ST, Ghosh S, Swarnakar S. The use of nano-quercetin to arrest mitochondrial damage and MMP-9 upregulation during prevention of gastric inflammation induced by ethanol in rat. Biomaterials. 2012;33(10):2991-3001.

92. Khalil NM, do Nascimento TCF, Casa DM, et al. Pharmacokinetics of curcumin-loaded PLGA and PLGA-PEG blend nanoparticles after oral administration in rats. Colloid Surface B Biointerfaces. 2013;101: 353-360.

93. Danhier F, Ansorena E, Silva JM, Coco R, Le Breton A, Preat V. PLGA-based nanoparticles: an overview of biomedical applications. $J$ Control Release. 2012;161(2):505-522.

94. Chitkara D, Nikalaje SK, Mittal A, Chand M, Kumar N. Development of quercetin nanoformulation and in vivo evaluation using streptozotocin induced diabetic rat model. Drug Deliv Transl Re. 2012;2(2): 112-123.

95. Walvekar MV, Pol SB, Deshmukh VM. Modulatory effect of fenugreek loaded PLGA nanoparticles on lipofuscinogenesis in pancreas of alloxan induced diabetic mice. Int $J$ Pharm Clin Res. 2016;8(1):22-25.

96. Ilaiyaraja N, Ambica P, Farhath K. Thymoquinone-loaded PLGA nanoparticles: antioxidant and anti-microbial properties. Int Curr Pharm J. 2013;2(12):202-207.

97. Ebtihal FA, Wagdy KB, Inas SG, Nagwa HAH, Ekram SA. Nanoparticles from of Costus speciosus extract improves the antidiabetic and antilipidemic effects against STZ-induced diabetes mellitus in Albino rats. Int J Pharm Sci Rev Res. 2014;29(1):279-288.

98. Lee SB, Yoo S, Ganesan P, Kwak HS. Physicochemical and antioxidative properties of Korean nanopowdered white ginseng. Int $J$ Food Sci Tech. 2013;48(10):2159-2165.

99. Fallahzadeh MK, Dormanesh B, Sagheb MM, et al. Effect of addition of silymarin to renin-angiotensin system on proteinuria in type 2 diabetic patients with overt nephropathy: a randomized, double-blind, placebo-controlled trial. Am J Kidney Dis. 2012;60(6):896-903.

100. Khazim K, Gorin Y, Cavaglieri RC, Abboud HE, Fanti P. The antioxidant silybin prevents high glucose-induced oxidative stress and podocyte injury in vitro and in vivo. Am J Physiol Renal Physiol. 2013;305(5):F691-F700.

101. Bouderba S. Protective effect of silibinin against liver oxidative stress in Psammomys obesus, model of insulin resistance and type 2 diabetes. Fund Clin Pharmacol. 2013;27:107-108.

102. Bouderba S, Sanchez-Martin C, Villanueva GR, Detaille D, Koceir EA. Beneficial effects of silibinin against the progression of metabolic syndrome, increased oxidative stress, and liver steatosis in Psammomys obesus, a relevant animal model of human obesity and diabetes. J Diabetes. 2014;6(2):184-192. 
103. McCarty MF. Potential utility of natural polyphenols for reversing fatinduced insulin resistance. Med Hypotheses. 2005;64(3):628-635.

104. Cheng BA, Gong H, Li XC, et al. Silibinin inhibits the toxic aggregation of human islet amyloid polypeptide. Biochem Bioph Res Commun. 2012; 419(3):495-499.

105. Haddad Y, Vallerand D, Brault A, Haddad PS. Antioxidant and hepatoprotective effects of silibinin in a rat model of nonalcoholic steatohepatitis. Evid Based Complement Alternat Med. 2011;2011: $1-10$

106. Milic N, Milosevic N, Suvajdzic L, Zarkov M, Abenavoli L. New therapeutic potentials of milk thistle (Silybum marianum). Nat Prod Commun. 2013;8(12):1801-1810.

107. Das S, Roy P, Pal R, Auddy RG, Chakraborti AS, Mukherjee A. Engineered silybin nanoparticles educe efficient control in experimental diabetes. PLoS One. 2014;9(7):e101818.

108. Ochi MM, Amoabediny G, Rezayat SM, Akbarzadeh A, Ebrahimi B. In vitro co-delivery evaluation of novel pegylated nano-liposomal herbal drugs of silibinin and glycyrrhizic acid (Nano-Phytosome) to hepatocellular carcinoma cells. Cell J. 2016;18(2):135-148

109. Kittl M, Beyreis M, Tumurkhuu M, et al. Quercetin stimulates insulin secretion and reduces the viability of rat INS-1 beta-cells. Cell Physiol Biochem. 2016;39(1):278-293.

110. D'Andrea G. Quercetin: a flavonol with multifaceted therapeutic applications? Fitoterapia. 2015;106:256-271.

111. Fujita A, Sarkar D, Wu SB, Kennelly E, Shetty K, Genovese MI. Evaluation of phenolic-linked bioactives of camu-camu (Myrciaria dubia Mc. Vaugh) for antihyperglycemia, antihypertension, antimicrobial properties and cellular rejuvenation. Food Res Int. 2015;77: 194-203.

112. MansouriE, Khorsandi L, Zare Moaiedi M. Grape seed proanthocyanidin extract improved some of biochemical parameters and antioxidant disturbances of red blood cells in diabetic rats. Iran J Pharm Res. 2015;14(1):329-334.

113. Cai XX, Bao L, Dai XQ, Ding Y, Zhang ZF, Li Y. Quercetin protects RAW264.7 macrophages from glucosamine-induced apoptosis and lipid accumulation via the endoplasmic reticulum stress pathway. Mol Med Rep. 2015;12(5):7545-7553.

114. Zhang YJ, Gan RY, Li S, et al. Antioxidant phytochemicals for the prevention and treatment of chronic diseases. Molecules. 2015;20(12): 21138-21156.

115. Clark JL, Zahradka P, Taylor CG. Efficacy of flavonoids in the management of high blood pressure. Nutr Rev. 2015;73(12):799-822.

116. Alam MM, Abdullah KM, Singh BR, Naqvi AH, Naseem I. Ameliorative effect of quercetin nanorods on diabetic mice: mechanistic and therapeutic strategies. RSC Adv. 2016;6(60):55092-55103.

117. Shao Y, Yu Y, Li C, Yu J, Zong RR, Pei CG. Synergistic effect of quercetin and 6-gingerol treatment in streptozotocin induced type 2 diabetic rats and poloxamer P-407 induced hyperlipidemia. RSC Adv. 2016; 6(15):12235-12242.

118. Yi Q, He XE, Luo KF, et al. Protection of long-term treatment with huang-lian-jie-du-tang on vascular endothelium in rats with type 2 diabetes mellitus. Curr Ther Res Clin E. 2012;73(6):174-185.

119. Xie W, Du L. Diabetes is an inflammatory disease: evidence from traditional Chinese medicines. Diabetes Obes Metab. 2011;13(4): 289-301.

120. Dinda B, SilSarma I, Dinda M, Rudrapaul P. Oroxylum indicum (L.) Kurz, an important Asian traditional medicine: from traditional uses to scientific data for its commercial exploitation. J Ethnopharmacol. 2015;161:255-278.

121. Liu SZ, Deng YX, Chen B, Zhang XJ, Shi QZ, Qiu XM. Antihyperglycemic effect of the traditional Chinese scutellaria-coptis herb couple and its main components in streptozotocin-induced diabetic rats. J Ethnopharmacol. 2013;145(2):490-498.

122. Waisundara VY, Siu SY, Hsu AN, Huang DJ, Tan BK. Baicalin upregulates the genetic expression of antioxidant enzymes in Type-2 diabetic Goto-Kakizaki rats. Life Sci. 2011;88(23-24): 1016-1025.
123. Song KH, Lee SH, Kim BY, Park AY, Kim JY. Extracts of scutellaria baicalensis reduced body weight and blood triglyceride in $\mathrm{db} / \mathrm{db}$ mice. Phytother Res. 2013;27(2):244-250.

124. Zhang JJ, Lv HX, Jiang K, Gao Y. Enhanced bioavailability after oral and pulmonary administration of baicalein nanocrystal. Int J Pharm. 2011;420(1):180-188.

125. Leung KCF, Seneviratne CJ, Li X, et al. Synergistic antibacterial effects of nanoparticles encapsulated with scutellaria baicalensis and pure chlorhexidine on oral bacterial biofilms. Nanomaterials. 2016; 6(4):61.

126. Zhao L, Wei YM, Huang Y, He B, Zhou Y, Fu JJ. Nanoemulsion improves the oral bioavailability of baicalin in rats: in vitro and in vivo evaluation. Int J Nanomedicine. 2013;8:3769-3779.

127. Wei Y, Guo J, Zheng X, et al. Preparation, pharmacokinetics and biodistribution of baicalin-loaded liposomes. Int J Nanomedicine. 2014;9: 3623-3630.

128. Stefanska B. Curcumin ameliorates hepatic fibrosis in type 2 diabetes mellitus - insights into its mechanisms of action. Br J Pharmacol. 2012;166(8):2209-2211.

129. Chuengsamarn S, Rattanamongkolgul S, Luechapudiporn R, Phisalaphong C, Jirawatnotai S. Curcumin extract for prevention of type 2 diabetes. Diabetes Care. 2012;35(11):2121-2127.

130. Maradana MR, Thomas R, O'Sullivan BJ. Targeted delivery of curcumin for treating type 2 diabetes. Mol Nutr Food Res. 2013;57(9): $1550-1556$.

131. Neerati P, Devde R, Gangi AK. Evaluation of the effect of curcumin capsules on glyburide therapy in patients with type-2 diabetes mellitus. Phytother Res. 2014;28(12):1796-1800.

132. Nabavi SF, Thiagarajan R, Rastrelli L, et al. Curcumin: a natural product for diabetes and its complications. Curr Top Med Chem. 2015;15(23): 2445-2455.

133. Yuan XH, Li HZ, Bai H, et al. Synthesis of novel curcumin analogues for inhibition of 11 beta-hydroxysteroid dehydrogenase type 1 with anti-diabetic properties. Eur J Med Chem. 2014;77:223-230.

134. Vahid F, Zand H, Nosrat-Mirshekarlou E, Najafi R, Hekmatdoost A. The role dietary of bioactive compounds on the regulation of histone acetylases and deacetylases: a review. Gene. 2015;562(1):8-15.

135. Sivabalan S, Anuradha CV. A comparative study on the antioxidant and glucose-lowering effects of curcumin and bisdemethoxycurcumin analog through in vitro assays. Int J Pharmacol. 2010;6(5):664-669.

136. Nahar PP, Slitt AL, Seeram NP. Anti-inflammatory effects of novel standardized solid lipid curcumin formulations. J Med Food. 2015;18(7): 786-792.

137. Prasad S, Tyagi AK, Aggarwal BB. Recent developments in delivery, bioavailability, absorption and metabolism of curcumin: the golden pigment from golden spice. Cancer Res Treat. 2014;46(1):2-18.

138. Ghosh D, Choudhury ST, Ghosh S, et al. Nanocapsulated curcumin: oral chemopreventive formulation against diethylnitrosamine induced hepatocellular carcinoma in rat. Chem Biol Interact. 2012;195(3): 206-214.

139. Hani U, Shivakumar HG. Solubility enhancement and delivery systems of curcumin a herbal medicine: a review. Curr Drug Deliv. 2014;11(6): 792-804.

140. Huang Y, Zhao YL, Liu F, Liu SQ. Nano traditional Chinese Medicine: current progresses and future challenges. Curr Drug Targets. 2015;16(13): 1548-1562.

141. Nguyen MH, Yu H, Kiew TY, Hadinoto K. Cost-effective alternative to nano-encapsulation: amorphous curcumin-chitosan nanoparticle complex exhibiting high payload and supersaturation generation. Eur J Pharm Biopharm. 2015;96:1-10.

142. Beloqui A, Coco R, Memvanga PB, Ucakar B, des Rieux A, Preat V. pH-sensitive nanoparticles for colonic delivery of curcumin in inflammatory bowel disease. Int J Pharmaceut. 2014;473(1-2): 203-212.

143. Kumar A, Ahuja A, Ali J, Baboota S. Curcumin loaded nano globules for solubility enhancement: preparation, characterization and ex vivo release study. J Nanosci Nanotechno. 2012;12(11):8293-8302. 
144. Sharma M, Sharma S, Sharma V, et al. Design of folic acid conjugated chitosan nano-cur-bioenhancers to attenuate the hormone-refractory metastatic prostate carcinoma by augmenting oral bioavailability. $R S C$ Adv. 2016;6(30):25137-25148

145. Kumar A, Ahuja A, Ali J, Baboota S. Curcumin-loaded lipid nanocarrier for improving bioavailability, stability and cytotoxicity against malignant glioma cells. Drug Deliv. 2016;23(1):214-229.

146. Zhang ZP, Zhang RJ, Zou LQ, et al. Encapsulation of curcumin in polysaccharide-based hydrogel beads: impact of bead type on lipid digestion and curcumin bioaccessibility. Food Hydrocolloid. 2016;58: 160-170.

147. Ramalingam P, Yoo SW, Ko YT. Nanodelivery systems based on mucoadhesive polymer coated solid lipid nanoparticles to improve the oral intake of food curcumin. Food Res Int. 2016;84:113-119.

148. Shin GH, Li J, Cho JH, Kim JT, Park HJ. Enhancement of curcumin solubility by phase change from crystalline to amorphous in Cur-TPGS nanosuspension. J Food Sci. 2016;81(2):N494-N501.

149. Molina-Bolivar JA, Galisteo-Gonzalez F. Olive-oil nanocapsules stabilized by HSA: influence of processing variables on particle properties. J Nanopart Res. 2015;17:391.

150. Ramalingam P, Ko YT. Enhanced oral delivery of curcumin from N-trimethyl chitosan surface-modified solid lipid nanoparticles: pharmacokinetic and brain distribution evaluations. Pharm Res. 2015;32(2): 389-402.

151. Grama CN, Suryanarayana P, Patil MA, et al. Efficacy of biodegradable curcumin nanoparticles in delaying cataract in diabetic rat model. PLoS One. 2013;8(10):e78217.

152. Joshi RP, Negi G, Kumar A, et al. SNEDDS curcumin formulation leads to enhanced protection from pain and functional deficits associated with diabetic neuropathy: an insight into its mechanism for neuroprotection. Nanomedicine. 2013;9(6):776-785.

153. Vecchione R, Quagliariello V, Calabria D, et al. Curcumin bioavailability from oil in water nano-emulsions: in vitro and in vivo study on the dimensional, compositional and interactional dependence. J Control Release. 2016;233:88-100.

154. Tsai YM, Jan WC, Chien CF, Lee WC, Lin LC, Tsai TH. Optimised nano-formulation on the bioavailability of hydrophobic polyphenol, curcumin, in freely-moving rats. Food Chem. 2011;127(3):918-925.

155. Wang JL, Ma WZ, Tu PF. The mechanism of self-assembled mixed micelles in improving curcumin oral absorption: in vitro and in vivo. Colloid Surf B Biointerfaces. 2015;133:108-119.

156. Lu Y, Yang JH, Li X, et al. Emodin, a naturally occurring anthraquinone derivative, suppresses IgE-mediated anaphylactic reaction and mast cell activation. Biochem Pharmacol. 2011;82(11):1700-1708.

157. Cao YN, Chang SF, Dong J, et al. Emodin ameliorates high-fat-diet induced insulin resistance in rats by reducing lipid accumulation in skeletal muscle. Eur J Pharmacol. 2016;780:194-201.

158. Xue JF, Ding WJ, Liu Y. Anti-diabetic effects of emodin involved in the activation of PPAR gamma on high-fat diet-fed and low dose of streptozotocin-induced diabetic mice. Fitoterapia. 2010;81(3):173-177.

159. Arvindekar A, More T, Payghan PV, Laddha K, Ghoshal N, Arvindekar A. Evaluation of anti-diabetic and alpha glucosidase inhibitory action of anthraquinones from Rheum emodi. Food Funct. 2015;6(8):2693-2700.

160. Bae UJ, Song MY, Jang HY, et al. Emodin isolated from Rheum palmatum prevents cytokine-induced beta-cell damage and the development of type 1 diabetes. J Funct Foods. 2015;16:9-19.

161. El Sayed AM, Ezzat SM, El Naggar MM, El Hawary SS. In vivo diabetic wound healing effect and HPLC-DAD-ESI-MS/MS profiling of the methanol extracts of eight Aloe species. Rev Bras Farmacogn 2016;26(3):352-362.

162. Abu Eid S, Adams M, Scherer T, et al. Emodin, a putative anti-diabetic active compound, impaired glucose tolerance in an obese mouse. Wien Klin Wochenschr. 2015;127(17-18):735-735.

163. Lin LF, Lin HM, Yin XB, et al. Characterization of the constituents in rat plasma after oral administration of radix polygoni multiflori extracts by ultra-performance liquid chromatography/quadrupole time-of-flight mass spectrometry. Biomed Chromatogr. 2015;29(10):1541-1547.
164. Zhang L, Chang JH, Zhang BQ, et al. The pharmacokinetic study on the mechanism of toxicity attenuation of rhubarb total free anthraquinone oral colon-specific drug delivery system. Fitoterapia. 2015;104: 86-96.

165. Wang SP, Chen TK, Chen RE, Hu YY, Chen MW, Wang YT. Emodin loaded solid lipid nanoparticles: preparation, characterization and antitumor activity studies. Int J Pharmaceut. 2012;430(1-2):238-246.

166. Zhang L, Ma WF, Li J, et al. Influence of processing on pharmacokinetic of typical constituents in radix polygoni multiflori after oral administration by LC-ESI-MS/MS. J Ethnopharmacol. 2013;148(1): 246-253.

167. Chang KC, Li LF, Sanborn TM, et al. Characterization of emodin as a therapeutic agent for diabetic cataract. J Nat Prod. 2016;79(5): 1439-1444.

168. Cai JZ, Chen SH, Zhang QW, Zhuang R, Zhang Y, Lin GY. Determination of emodin in rat plasma by gradient elution LC-ESI-MS and its application to pharmacokinetics. Lat Am J Pharm. 2013;32(2): 269-274.

169. Zhang YX, Li JS, Peng WW, et al. Comparative pharmacokinetics of aloe-emodin, rhein and emodin determined by liquid chromatographymass spectrometry after oral administration of a rhubarb peony decoction and rhubarb extract to rats. Pharmazie. 2013;68(5):333-339.

170. Ren H, Zhu C, Li ZH, Yang W, Song E. Emodin-loaded magnesium silicate hollow nanocarriers for anti-angiogenesis treatment through inhibiting VEGF. Int J Mol Sci. 2014;15(9):16936-16948.

171. Lu K, Xie S, Han S, et al. Preparation of a nano emodin transfersome and study on its anti-obesity mechanism in adipose tissue of dietinduced obese rats. J Transl Med. 2014;12:72.

172. Shi YB, Li HL, Li JC, et al. Development, optimization and evaluation of emodin loaded nanoemulsion prepared by ultrasonic emulsification. J Drug Deliv Sci Tec. 2015;27:46-55.

173. Shi YB, Li JC, Ren Y, et al. Pharmacokinetics and tissue distribution of emodin loaded nanoemulsion in rats. J Drug Deliv Sci Tec. 2015;30: 242-249

174. Al-Rejaie SS, Aleisa AM, Abuohashish HM, et al. Naringenin neutralises oxidative stress and nerve growth factor discrepancy in experimental diabetic neuropathy. Neurol Res. 2015;37(10):924-933.

175. Bhattacharya S, Oksbjerg N, Young JF, Jeppesen PB. Caffeic acid, naringenin and quercetin enhance glucose-stimulated insulin secretion and glucose sensitivity in INS-1E cells. Diabetes Obes Metab. 2014;16(7): 602-612.

176. Hasanein P, Fazeli F. Role of naringenin in protection against diabetic hyperalgesia and tactile allodynia in male Wistar rats. $J$ Physiol Biochem. 2014;70(4):997-1006.

177. Keshari AK, Kumar G, Kushwaha PS, et al. Isolated flavonoids from Ficus racemosa stem bark possess antidiabetic, hypolipidemic and protective effects in albino Wistar rats. J Ethnopharmacol. 2016;181: 252-262.

178. Koch CE, Ganjam GK, Steger J, et al. The dietary flavonoids naringenin and quercetin acutely impair glucose metabolism in rodents possibly via inhibition of hypothalamic insulin signalling. Br J Nutr. 2013;109(6): 1040-1051.

179. Priscilla DH, Roy D, Suresh A, Kumar V, Thirumurugan K. Naringenin inhibits alpha-glucosidase activity: a promising strategy for the regulation of postprandial hyperglycemia in high fat diet fed streptozotocin induced diabetic rats. Chem Biol Interact. 2014;210:77-85.

180. Zeng B, Chen K, Du P, et al. Phenolic compounds from clinopodium chinense (Benth.) O. Kuntze and their inhibitory effects on alpha-glucosidase and vascular endothelial cells injury. Chem Biodivers. 2016;13(5):596-601.

181. Dalagnol M, de Bernardi LS, Lemos-Senna E, Cardoso SG. Development and validation of a RP-HPLC method to quantify naringenin in Lecithin/Chitosan nano- and microparticle suspensions. Lat Am J Pharm. 2013;32(2):214-219.

182. Fathi M, Varshosaz J. Novel hesperetin loaded nanocarriers for food fortification: production and characterization. J Funct Foods. 2013; 5(3):1382-1391. 
183. Kanaze FI, Kokkalou E, Niopas I, Georgarakis M, Stergiou A, Bikiaris D. Thermal analysis study of flavonoid solid dispersions having enhanced solubility. J Therm Anal Calorim. 2006;83(2): 283-290.

184. Kumar SP, Birundha K, Kaveri K, Devi KT. Antioxidant studies of chitosan nanoparticles containing naringenin and their cytotoxicity effects in lung cancer cells. Int J Biol Macromol. 2015;78:87-95.

185. Shpigelman A, Shoham Y, Israeli-Lev G, Livney YD. beta-Lactoglobulin-naringenin complexes: nano-vehicles for the delivery of a hydrophobic nutraceutical. Food Hydrocolloid. 2014;40: 214-224.

186. Khan AW, Kotta S, Ansari SH, Sharma RK, Ali J. Self-nanoemulsifying drug delivery system (SNEDDS) of the poorly water-soluble grapefruit flavonoid naringenin: design, characterization, in vitro and in vivo evaluation. Drug Deliv. 2015;22(4):552-561.

187. Yen FL, Wu TH, Lin LT, Cham TM, Lin CC. Naringenin-loaded nanoparticles improve the physicochemical properties and the hepatoprotective effects of naringenin in orally-administered rats with $\mathrm{CCl}(4)-$ induced acute liver failure. Pharm Res. 2009;26(4):893-902.

188. Ji P, Yu T, Liu Y, et al. Naringenin-loaded solid lipid nanoparticles: preparation, controlled delivery, cellular uptake, and pulmonary pharmacokinetics. Drug Des Dev Ther. 2016;10:911-925.

189. Abuohashish HM, Al-Rejaie SS, Al-Hosaini KA, Parmar MY, Ahmed MM. Alleviating effects of morin against experimentallyinduced diabetic osteopenia. Diabetol Metab Syndr. 2013;5(1):5.

190. AlSharari SD, Al-Rejaie SS, Abuohashish HM, Aleisa AM, Parmar MY, Ahmed MM. Ameliorative potential of morin in streptozotocininduced neuropathic pain in rats. Trop J Pharm Res. 2014;13(9): 1429-1436.

191. Komirishetty P, Areti A, Sistla R, Kumar A. Morin mitigates chronic constriction injury (CCI)-induced peripheral neuropathy by inhibiting oxidative stress induced PARP over-activation and neuroinflammation. Neurochem Res. 2016;41(8):2029-2042.

192. Naowaboot J, Wannasiri S, Pannangpetch P. Morin attenuates hepatic insulin resistance in high-fat-diet-induced obese mice. J Physiol Biochem. 2016;72(2):269-280.

193. Taguchi K, Hida M, Matsumoto T, Ikeuchi-Takahashi Y, Onishi H, Kobayashi T. Effect of short-term polyphenol treatment on endothelial dysfunction and thromboxane A(2) levels in streptozotocin-induced diabetic mice. Biol Pharm Bull. 2014;37(6):1056-1061.

194. Caselli A, Cirri P, Santi A, Paoli P. Morin: a promising natural drug. Curr Med Chem. 2016;23(8):774-791.

195. Paoli P, Cirri P, Caselli A, et al. The insulin-mimetic effect of morin: a promising molecule in diabetes treatment. Biochim Biophys Acta. 2013;1830(4):3102-3111.

196. Zhang J, Li J, Ju Y, Fu Y, Gong T, Zhang Z. Mechanism of enhanced oral absorption of morin by phospholipid complex based self-nanoemulsifying drug delivery system. Mol Pharm. 2015;12(2): 504-513.

197. Zhang J, Peng Q, Shi S, et al. Preparation, characterization, and in vivo evaluation of a self-nanoemulsifying drug delivery system (SNEDDS) loaded with morin-phospholipid complex. Int J Nanomedicine. 2011;6: $3405-3414$.

198. Zhang J, Shuai X, Li J, Xiang N, Gong T, Zhang Z. Biodistribution, hypouricemic efficacy and therapeutic mechanism of morin phospholipid complex loaded self-nanoemulsifying drug delivery systems in an experimental hyperuricemic model in rats. $J$ Pharm Pharmacol. 2016;68(1):14-25

199. Choi YA, Yoon YH, Choi K, et al. Enhanced oral bioavailability of morin administered in mixed micelle formulation with PluronicF127 and Tween80 in rats. Biol Pharm Bull. 2015;38(2):208-217.

200. Ikeuchi-Takahashi $Y$, Ishihara $C$, Onishi H. Formulation and evaluation of morin-loaded solid lipid nanoparticles. Biol Pharm Bull. 2016;39(9): $1514-1522$.

201. Fu Z, Zhang W, Zhen W, et al. Genistein induces pancreatic beta-cell proliferation through activation of multiple signaling pathways and prevents insulin-deficient diabetes in mice. Endocrinology. 2010;151(7): 3026-3037.
202. Getek M, Czech N, Muc-Wierzgon M, Grochowska-Niedworok E, Kokot T, Nowakowska-Zajdel E. The active role of leguminous plant components in type 2 diabetes. Evid Based Complement Alternat Med. 2014;2014:293961.

203. Gilbert ER, Liu D. Anti-diabetic functions of soy isoflavone genistein: mechanisms underlying its effects on pancreatic beta-cell function. Food Funct. 2013;4(2):200-212.

204. Kwon DY, Hong SM, Ahn IS, Kim MJ, Yang HJ, Park S. Isoflavonoids and peptides from meju, long-term fermented soybeans, increase insulin sensitivity and exert insulinotropic effects in vitro. Nutrition. 2011; 27(2):244-252.

205. Mezei O, Banz WJ, Steger RW, Peluso MR, Winters TA, Shay N. Soy isoflavones exert antidiabetic and hypolipidemic effects through the PPAR pathways in obese Zucker rats and murine RAW 264.7 cells. J Nutr. 2003;133(5):1238-1243.

206. Rauter AP, Martins A, Borges C, et al. Antihyperglycaemic and protective effects of flavonoids on streptozotocin-induced diabetic rats. Phytother Res. 2010;24(Suppl 2):S133-S138.

207. Saha S, Sadhukhan P, Sil PC. Genistein: a phytoestrogen with multifaceted therapeutic properties. Mini Rev Med Chem. 2014;14(11): 920-940.

208. Andrade JE, Twaddle NC, Helferich WG, Doerge DR. Absolute bioavailability of isoflavones from soy protein isolate-containing food in female BALB/c mice. J Agr Food Chem. 2010;58(7): 4529-4536.

209. Soucy NV, Parkinson HD, Sochaski MA, Borghoff SJ. Kinetics of genistein and its conjugated metabolites in pregnant Sprague-Dawley rats following single and repeated genistein administration. Toxicol Sci. 2006;90(1):230-240.

210. Cimafranca MA, Davila J, Ekman GC, et al. Acute and chronic effects of oral genistein administration in neonatal mice. Biol Reprod. 2010;83(1): 114-121.

211. Aditya NP, Shim M, Lee I, Lee Y, Im MH, Ko S. Curcumin and genistein coloaded nanostructured lipid carriers: in vitro digestion and antiprostate cancer activity. J Agr Food Chem. 2013;61(8):1878-1883.

212. Gavin A, Pham JTH, Wang DW, Brownlow B, Elbayoumi TA. Layered nanoemulsions as mucoadhesive buccal systems for controlled delivery of oral cancer therapeutics. Int $J$ Nanomedicine. 2015;10: 1569-1584.

213. Wu BQ, Liang Y, Tan Y, et al. Genistein-loaded nanoparticles of star-shaped diblock copolymer mannitol-core PLGA-TPGS for the treatment of liver cancer. Mater Sci Eng C Mater Biol Appl. 2016;59: 792-800.

214. Kwon SH, Kim SY, Ha KW, et al. Pharmaceutical evaluation of genisteinloaded pluronic micelles for oral delivery. Arch Pharm Res. 2007;30(9): $1138-1143$.

215. Shehata EM, Elnaggar YS, Galal S, Abdallah OY. Self-emulsifying phospholipid pre-concentrates (SEPPs) for improved oral delivery of the anti-cancer genistein: development, appraisal and ex-vivo intestinal permeation. Int J Pharm. 2016;511(2):745-756.

216. El-Marasy SA, Abdallah HMI, El-Shenawy SM, El-Khatib AS, ElShabrawy OA, Kenawy SA. Anti-depressant effect of hesperidin in diabetic rats. Can J Physiol Pharm. 2014;92(11):945-952.

217. Hernandez-Saavedra D, Perez-Ramirez IF, Ramos-Gomez M, Mendoza-Diaz S, Loarca-Pina G, Reynoso-Camacho R. Phytochemical characterization and effect of Calendula officinalis, Hypericum perforatum, and Salvia officinalis infusions on obesity-associated cardiovascular risk. Med Chem Res. 2016;25(1):163-172.

218. Roohbakhsh A, Parhiz H, Soltani F, Rezaee R, Iranshahi M. Molecular mechanisms behind the biological effects of hesperidin and hesperetin for the prevention of cancer and cardiovascular diseases. Life Sci. 2015;124:64-74.

219. Sharma M, Akhtar N, Sambhav K, Shete G, Bansal AK, Sharma SS. Emerging potential of citrus flavanones as an antioxidant in diabetes and its complications. Curr Top Med Chem. 2015;15(2):187-195.

220. Shi XP, Liao S, Mi HJ, et al. Hesperidin prevents retinal and plasma abnormalities in streptozotocin-induced diabetic rats. Molecules. 2012;17(11):12868-12881. 
221. Actis-Goretta L, Dew TP, Leveques A, et al. Gastrointestinal absorption and metabolism of hesperetin-7-O-rutinoside and hesperetin-7-O-glucoside in healthy humans. Mol Nutr Food Res. 2015; 59(9):1651-1662.

222. Escudero-Lopez B, Calani L, Fernandez-Pachon MS, et al. Absorption, metabolism, and excretion of fermented orange juice (poly)phenols in rats. Biofactors. 2014;40(3):327-335.

223. Shete G, Pawar YB, Thanki K, Jain S, Bansal AK. Oral bioavailability and pharmacodynamic activity of hesperetin nanocrystals generated using a novel bottom-up technology. Mol Pharm. 2015;12(4): $1158-1170$.

224. Fathi M, Varshosaz J, Mohebbi M, Shahidi F. Hesperetin-loaded solid lipid nanoparticles and nanostructure lipid carriers for food fortification: preparation, characterization, and modeling. Food Bioprocess Technol. 2012;6(6):1464-1475.

225. Mauludin RMR. Physicochemical properties of hesperidin nanocrystal. Int J Pharm Pharm Sci. 2013;5(3):954-960.

226. Gurushankar K, Gohulkumar M, Rajendra Prasad N, Krishnakumar N. Synthesis, characterization andin vitroanti-cancer evaluation of hesperetin-loaded nanoparticles in human oral carcinoma (KB) cells. Adv Nat Sci: Nanosci Nanotechnol. 2013;5(1):015006.

227. Cheong SH, Furuhashi K, Ito K, et al. Daidzein promotes glucose uptake through glucose transporter 4 translocation to plasma membrane in L6 myocytes and improves glucose homeostasis in Type 2 diabetic model mice. J Nutr Biochem. 2014;25(2):136-143.

228. Cheong SH, Furuhashi K, Ito K, et al. Antihyperglycemic effect of equol, a daidzein derivative, in cultured L6 myocytes and ob/ob mice. Mol Nutr Food Res. 2014;58(2):267-277.
229. Ding M, Pan A, Manson JE, et al. Consumption of soy foods and isoflavones and risk of type 2 diabetes: a pooled analysis of three US cohorts. Eur J Clin Nutr. 2016;70(12):1381-1387.

230. Hosseini M, Asgary S, Najafi S. Inhibitory potential of pure isoflavonoids, red clover, and alfalfa extracts on hemoglobin glycosylation. ARYA Atheroscler. 2015;11(2):133-138.

231. Park MH, Ju JW, Kim M, Han JS. The protective effect of daidzein on high glucose-induced oxidative stress in human umbilical vein endothelial cells. Z Naturforsch C. 2016;71(1-2):21-28.

232. Park MH, Ju JW, Park MJ, Han JS. Daidzein inhibits carbohydrate digestive enzymes in vitro and alleviates postprandial hyperglycemia in diabetic mice. Eur J Pharmacol. 2013;712(1-3):48-52.

233. Talaei M, Lee BL, Ong CN, et al. Urine phyto-oestrogen metabolites are not significantly associated with risk of type 2 diabetes: the Singapore Chinese health study. Br J Nutr. 2016;115(9):1607-1615.

234. Zang Y, Igarashi K, Yu C. Anti-obese and anti-diabetic effects of a mixture of daidzin and glycitin on $\mathrm{C} 57 \mathrm{BL} / 6 \mathrm{~J}$ mice fed with a high-fat diet. Biosci Biotechnol Biochem. 2015;79(1):117-123.

235. Zhang Z, Huang Y, Gao F, Bu H, Gu W, Li Y. Daidzein-phospholipid complex loaded lipid nanocarriers improved oral absorption: in vitro characteristics and in vivo behavior in rats. Nanoscale. 2011;3(4): 1780-1787.

236. Zhang Z, Huang Y, Gao F, et al. A self-assembled nanodelivery system enhances the oral bioavailability of daidzein: in vitro characteristics and in vivo performance. Nanomedicine (Lond). 2011;6(8) 1365-1379.
International Journal of Nanomedicine

\section{Publish your work in this journal}

The International Journal of Nanomedicine is an international, peerreviewed journal focusing on the application of nanotechnology in diagnostics, therapeutics, and drug delivery systems throughout the biomedical field. This journal is indexed on PubMed Central, MedLine, CAS, SciSearch $®$, Current Contents $\AA /$ Clinical Medicine,

\section{Dovepress}

Journal Citation Reports/Science Edition, EMBase, Scopus and the Elsevier Bibliographic databases. The manuscript management system is completely online and includes a very quick and fair peer-review system, which is all easy to use. Visit http://www.dovepress.com/ testimonials.php to read real quotes from published authors. 